UCRL-ID-121651

\title{
A Procedure for Diamond Turning KDP Crystals
}

\author{
R. C. Montesanti \\ S. L. Thompson
}

July 7, 1995

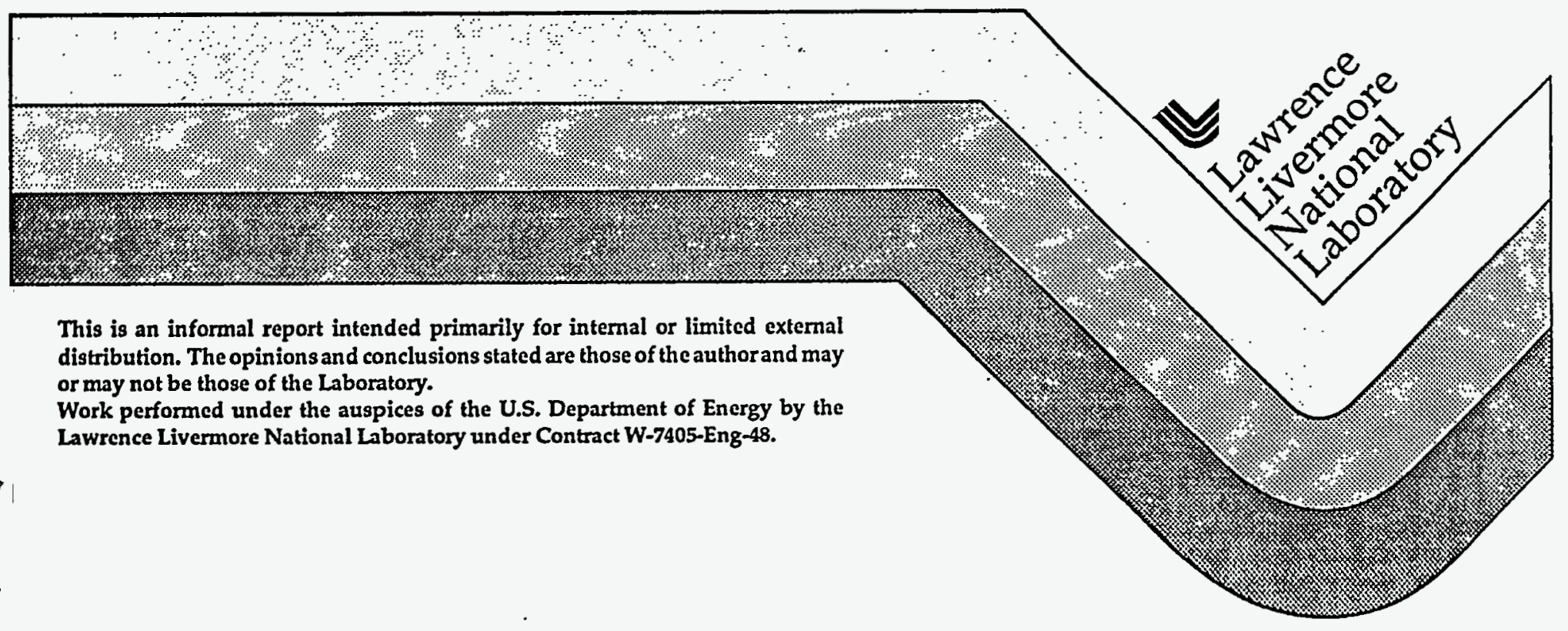

DISTRIBUTION OF THIS DOCUMENT IS UNLIMITED BS 


\section{DISCLAIMER}

This document was prepared as an account of work sponsored by an agency of the United States Government. Neither the United States Government nor the University of California nor any of their employees, makes any warranty, express or implied, or assumes any legal liability or responsibility for the accuracy, completeness, or usefulness of any information, apparatus, product, or process disclosed, or represents that its use would not infringe privately owned rights. Reference herein to any specific commercial products, process, or service by trade name, trademark, manufacturer, or otherwise, does not necessarily constitute or imply its endorsement, recommendation, or favoring by the United States Government or the University of California. The views and opinions of authors expressed herein do not necessarily state or reflect those of the United States Government or the University of California, and shall not be used for advertising or product endorsement purposes.

This report has been reproduced directly from the best available copy.

Available to DOE and DOE contractors from the Office of Scientific and Technical Information

P.O. Box 62, Oak Ridge, TN 37831

Prices available from (615) 576-8401, FTS 626-8401

Available to the public from the

National Technical Information Service

U.S. Department of Commerce

5285 Port Royal Rd,

Springfield, VA 22161 


\section{DISCLAIMER}

Portions of this document may be illegible in electronic image products. Images are produced from the best available original document. 


\title{
A Procedure for Diamond Turning KDP Crystals
}

\subsection{Abstract}

\author{
Richard C. Montesanti \\ Samuel L. Thompson \\ Lawrence Livermore National Laboratory \\ 7 July 1995
}

A procedure and the equipment necessary for single-point diamond flycutting (loosely referred to as diamond turning) potassium di-hydrogen phosphate (KDP) crystals are described. It is based on current KDP diamond turning activities at the Lawrence Livermore National Laboratory (LLNL), drawing upon knowledge from the Nova crystal finishing development during the 1980's and incorporating refinements from our efforts during 1995 . In addition to describing a step-by-step process for diamond turning KDP, specific discussions are included on the necessary diamond tool geometry and edge sharpness, cutting fluid, and crystal preparation, handling, cleaning, and inspection. The authors presuppose that the reader is already familiar with diamond turning practices.

Keywords: KDP, potassium di-hydrogen phosphate, crystals, diamond turning

\subsection{Summary}

KDP crystals are used in modern high energy solid state lasers as harmonic frequency converters and polarization rotators in Pockels cells.1, 2 Experience with the Nova and Beamlet lasers at the Lawrence Livermore National Laboratory (LLNL) has shown that the laser damage threshold level of crystal surfaces finished by single-point diamond flycutting (loosely referred to as diamond turning) are higher than that of the bulk material. ${ }^{3}$ Thus, the bulk material properties, and not the finishing process limits the fluence levels that the crystals can safely withstand, and diamond turning remains the preferred method for finishing them. Current state-of-the-art diamond turning of KDP produces surfaces with $10 \AA-30 \AA \mathrm{rms}$ roughness when measured with a cut-off length of $0.7 \mathrm{~mm}$.

Figure 1 depicts a two-axis diamond turning machine (DTM) set up in a flycutting configuration. It has two orthogonal axes $(X$ and $Z)$ that lie in a horizontal plane. The Z-axis carriage carries a spindle whose axis is parallel to the Z-axis. A singlepoint diamond tool is mounted at a fixed distance from the spindle centerline to form a flycutter. The workpiece (KDP crystal) is mounted on a vacuum chuck attached to the $\mathrm{X}$-axis carriage. With the $\mathrm{Z}$-axis carriage held stationary, the $\mathrm{X}$-axis carriage feeds the workpiece across the flycutter to produce the final (flat) figure and finish on the face opposite the chuck surface. A vertical plane two-axis DTM may also be used, but the issue of KDP debris removal from the work piece during finishing may be more troublesome. 


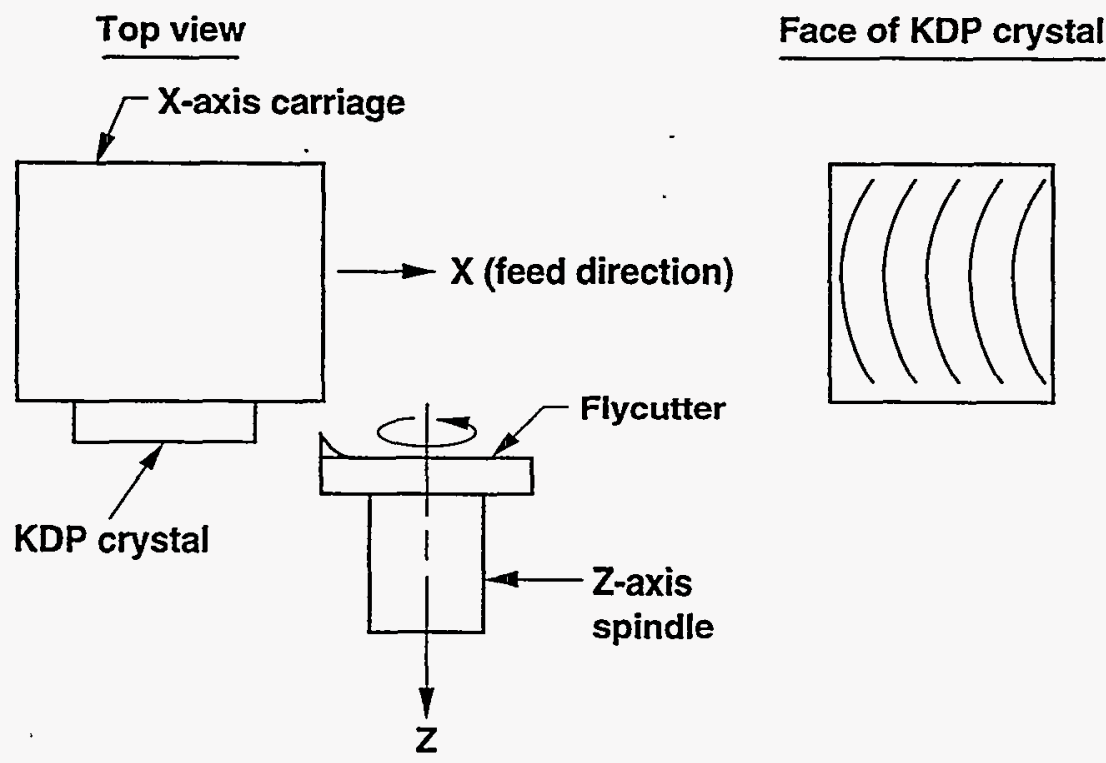

Figure 1. A two-axis diamond turning machine configured for flycutting KDP.

\subsection{Equipment}

3.1 A 2-axis diamond turning machine that can be used in a flycutting configuration. The slide on which the crystal is mounted should have a minimum length of travel from the start-of-cutting position to the end-ofcutting position equal to the radius of the flycutter plus one-half the width of the crystal, plus clearance $(\approx 6 \mathrm{~mm})$. At the end-of-cutting position, the crystal should have its centerline coincident with the spindle centerline.

3.2 A flycutter that holds a single-point diamond tool on a diameter with a minimum dimension equal to the diagonal face dimension of the KDP crystal plus clearance $(\approx 12 \mathrm{~mm})$. The face of the crystal is assumed to be square. We have found that a $400 \mathrm{~mm}$ diameter flycutter with a rotational speed of $630-R P M$ can produce surface finishes as good as $20 \AA \mathrm{rms}$ on $50 \mathrm{~mm} \times 50 \mathrm{~mm}$ crystals when measured with a cut-off length of $0.7 \mathrm{~mm}$.

3.3 An aluminum vacuum chuck for holding the crystal to be flycut. We have had success with land widths of $0.05 \mathrm{~mm}-0.13 \mathrm{~mm}$, spaced $2.5 \mathrm{~mm}$ apart. 4,5

3.4 A freshly sharpened single-point diamond tool for finishing the crystal. The tool should have a nose radius of $5.1 \mathrm{~mm}$ to $7.6 \mathrm{~mm}$ and be oriented so that it cuts at a $45^{\circ}$ negative rake angle. $4,6,7,8,9$

3.5 A freshly sharpened single-point diamond tool for finishing the vacuum chuck. The tool should have a nose radius of $1 \mathrm{~mm}$ and be oriented so that it cuts at a $0^{\circ}$ rake angle. ${ }^{5}$

3.6 A clean very-fine single-cut file for chamfering the edges of the crystal. 
3.7 A flood coolant system to introduce light food-grade mineral oil onto the crystal at the location of the tool tip. 10

3.8 A clean gage-block stone for dressing the vacuum chuck.

3.9 A supply of clean toluene for cleaning the mineral oil off of the finished crystal.

3.10 Clean lint-free lens tissue for drag-wiping the finished crystal with toluene.

\subsection{Procedure}

4.1 Flycut the vacuum chuck to generate a crystal mounting surface that will be parallel to the surface generated by the finish cuts on the crystal faces. The default finishing schedule for the vacuum chuck is the crystal finishing schedule shown in Table 1.5

4.2 Lightly dress the finished vacuum chuck with the gage-block stone to remove any burrs or dirt. 4,5 This should be done wet using the same cutting fluid that the crystal will be finished with. The object is to remove dirt and burrs from the vacuum chuck lands without changing the surface that they form. Use a single very light pass over the entire surface, realizing that the narrow lands will allow immediate intimate contact to be made between the stone and the chuck.

4.3 Gently chamfer the tool exit edges on the faces of the crystal to be finished by draw-filing away from the face at a $45^{\circ}$ angle.4,5,6 A $0.1 \mathrm{~mm}-0.2 \mathrm{~mm}$ chamfer should be sufficient for preventing edge chip-out during diamond turning.

4.4 Mount the crystal onto the vacuum chuck to finish the first face. This should be done with the oil shower on - wetting the chuck and the face of the crystal that will contact it. 4,5 To avoid scratching the crystal, do not allow it to slide against the vacuum chuck. The use of locator pins that contact the edges of the crystal can facilitate proper mounting.

4.5 Flycut the crystal using the finishing schedule shown in Table 1. This schedule is currently being used at LLNL, and is based on our past and recent development efforts. ${ }^{4,6,7,8}$ Maintain a constant flood of clean light food-grade mineral oil over the crystal face during cutting to remove KDP debris from the tool and workpiece, and to maintain a uniform crystal temperature. 


\begin{tabular}{|c|c|c|c|}
\hline $\begin{array}{c}\text { depth of cut } \\
(\mu \mathrm{m})\end{array}$ & $\begin{array}{c}\text { cross-slide } \\
\text { feedrate } \\
(\mathrm{mm} / \mathrm{min})\end{array}$ & $\begin{array}{c}\text { cross-slide } \\
\text { feedrate @ } \\
630 \mathrm{RPM} \\
(\mu \mathrm{m} / \mathrm{rev})\end{array}$ & $\begin{array}{c}\text { theoretical P-V finish } \\
\text { w/ a 5mm tool nose } \\
\text { radius and 630 RPM } \\
(\AA)\end{array}$ \\
\hline 12.5 & 25 & 40 & 400 \\
\hline 10.0 & 25 & 40 & 400 \\
\hline 7.5 & 25 & 40 & 400 \\
\hline 5.0 & 25 & 40 & 400 \\
\hline 2.5 & 12 & 19 & 90 \\
\hline 1.2 & 7.6 & 12 & 36 \\
\hline 0.5 & 5.0 & 8 & 16 \\
\hline 0.5 & 2.5 & 4 & 4 \\
\hline
\end{tabular}

Table 1. Finishing schedule for the KDP crystal.

4.6 Remove the crystal from the vacuum chuck and submerse it into successively cleaner containers of toluene to remove the mineral oil, then drag wipe the finished surface with clean toluene and a lens tissue. ${ }^{4}$

4.7 Inspect the finished surface.

4.8 Clean the vacuum chuck with the gage-block stone and the same (clean) cutting fluid that the crystal will be finished with.

4.9 Mount the crystal onto the vacuum chuck to finish the second face.

\subsection{Specific Discussions}

\subsection{Diamond Tool Geometry}

Unlike many of the other diamond-turnable materials such as aluminum, copper, or gold, KDP is a brittle material. The same $0^{\circ}$ or slightly positive tool rake angle that works successfully for the metals will cause massive cratering damage to KDP. Cratering is dramatically reduced if the crystal is. cut with a $45^{\circ}$ negative rake angle, which puts the surface into compression and minimizes the tensile stresses that cause cratering. $4,6,7,8,9$

A large tool nose radius tools plays an important role in reducing cratering. Additionally, the large radius improves the surface finish for a given feedrate of the crystal across the flycutter. We are currently using diamond tools with a $7.62 \mathrm{~mm}$ nose radius. With an adequately stiff enough machine and good cutting fluid conditions, a larger tool nose radius may lead to improved finishes. 


\subsection{Diamond Tool Edge Sharpness}

The edge characteristics of the diamond tool are one of the least understood aspects of the KDP finishing process. Our experience has been that one tool will cut well while another apparently identical tool (as revealed by a visible light microscope) will cut poorly. Although commonly used to evaluate tool edge sharpness, a visible light microscope does not have the resolution necessary (below $\approx 0.5 \mu \mathrm{m}$ ) to determine if a tool is sharp enough. It will however reveal gross imperfections that render a tool useless. Additional research into tool edge evaluation is required. In the meantime, we have had success by using freshly sharpened diamond tools.

Diamond tool wear is very low when cutting KDP. ${ }^{8}$ We have found that tool life is limited by damage rather than wear. Chipping of the tool edge is the most obvious defect, and this can often be seen by examination of the tool with a visible light microscope. A "rainbow" appearance of the finished crystal surface usually indicates a chipped tool edge. Careless handling of the tool or cutting a contaminated crystal surface are almost always the cause of tool edge damage.

Because the tool passes over the entire surface of the crystal face being finished it will encounter any contamination - abrasive particles from a previous lapping or polishing operation for instance - that is on or embedded into the surface or edges of the part. If we know or suspect that the crystal was polished, we treat it as if residual abrasive particles are embedded in the surface. The edges along the face to be machined are first chamfered, as described in Sections 4.3 and 5.4, then the crystal face is rough finished with a high-speed steel or cubic boron nitride (CBN) tool at a $0^{\circ}$ rake angle. This causes massive cratering damage and induces residual stresses into the surface of the part, which are both removed during the finishing operation with a diamond tool. When contamination causes a diamond tool to chip, either the abrasive particle or diamond tool chip can be driven deeper into the part by the $45^{\circ}$ negative rake angle, which will then damage a new tool unless it is removed by the above mentioned procedure.

\subsection{Cutting Fluid}

A cutting fluid shower over the work piece and tool has proven to be necessary to successfully diamond turn KDP. 4,5 We are currently using light food-grade mineral oil.10 If a recirculating system is used, then the oil needs to be filtered to remove the KDP debris.

The quality of the finished crystal surface is very sensitive to the fluid flow over the part. Several defects have been observed in finished surfaces that seem to be related to the cutting fluid. Too little fluid flow leaves KDP debris on the part. While the surface finish may be very good, scattering produced by the debris will reduce the clarity of the surface. Too much fluid flow appears to exacerbate the hydrodynamic effects between the tool and the work piece, which can degrade the surface roughness and make it difficult to maintain a uniform depth of cut over the entire 
crystal surface.

Particular attention must be paid to minimizing the amount of splashing of the cutting fluid, which can add to the machine asynchronous motion and increase the roughness of the finished crystal. In addition, the period and magnitude of the temperature fluctuations of the oil shower and room air must be considered when assessing depth of cut and crystal surface waviness issues.

\subsection{Crystal Edge Chamfers}

The tool exit edges of the crystal need to be chamfered.4,5,6 Without them, massive chipping will occur as the unsupported edge goes into tension from the tool forces. Chamfering all of the edges helps protect them against handling damage. Chamfers can be cut by draw-filing at $45^{\circ}$ away from the crystal face with a very fine file. Abrasives should not be used to produce or clean-up a chamfer because the diamond tool will be damaged if it encounters any of the remaining abrasive particles.

\subsection{KDP Finishing Schedule}

The KDP finishing schedule is an area of ongoing research. We are currently using the schedule shown in Table 1 to produce surfaces with a $10 \AA-30 \AA$ rms roughness when measured with a cut-off length of $0.7 \mathrm{~mm}$. Our experience has shown that depths of cut greater than $25 \mu \mathrm{m}$ cause massive cratering of the surface and break-out along the tool exit edges of the crystal. If faster stock removal is desired, a flycutter utilizing multiple tools radially and axially offset from each other can be used.4,5

The finishing schedule consists of a series of taper-down depths of cut. Ideally, each finishing pass removes the surface cratering and subsurface damage caused by the previous one, and produces its own but smaller - and eventually acceptable or negligible with the last pass - amount of damage.11, 12 The depth of cut and feedrate of the last two or three finishing passes are very dependent on the asynchronous motion and stiffness characteristics of the DTM being used. If the machine has very low levels of asynchronous motion, then feedrates approaching those for the desired theoretical finish can be used. If the levels are fairly high, or the machine stiffness is not adequate for maintaining the desired depths of cut, then slower feedrates should be used.

\subsection{Handling KDP Crystals}

KDP has several special handling requirements. Since it is hydroscopic, it readily dissolves in water and should therefore not be exposed to moisture. KDP is brittle and is easily damaged by mechanical impact. The combination of high brittleness with a relatively high coefficient of expansion and low thermal conductivity makes $\mathrm{KDP}$ very vulnerable to breaking by thermal shock. 
To protect the material from moisture several handling precautions need to be observed. First and most obvious, gloves need to be worn to protect finished surfaces from moisture in the handler's skin. The gloves should be made of a material that is not attacked by the cutting oils or solvents used in cleaning the parts, and should not contaminate the part (with talc for instance). We have found that the disposable polyethylene gloves used by food handlers work satisfactory, albeit poorly fitting and clumsy to use. Moisture from breathing, talking, coughing, and sneezing is another source of contamination. Face masks should be used when handling finished crystals. Finished crystals should be stored with desiccant or some other precaution to insure that condensation does not form on them. It may also be necessary to insure that cutting and cleaning fluids are free of water contamination. In addition, the temperature and humidity of the rooms where crystals will be exposed to the ambient environment need to be kept under reasonable control. As long as there are no sudden temperature changes, a relative humidity under $50 \%$ $60 \%$ (well below the dew point) appears to be acceptable.

Beacause the crystals are very brittle, the edges and corners are easily damaged by the slightest mechanical impact. With larger crystals this becomes a two fold problem; the increased size and weight make it more difficult to handle the part, and the increased mass stores more kinetic energy during movement which makes impact even more devastating

Thermal shock is a problem, especially with larger crystals. Cleaning fluids with a rapid evaporation rate should be avoided, since they can cause sufficiently fast enough local cooling to cause damage. In addition, they can also cause moisture from the ambient air to condense on the crystal.

\subsection{Cleaning KDP Crystals}

After a KDP crystal is diamond turned, the residual cutting fluids have to be removed so that the part can be inspected. The crystal also has to be cleaned before mounting it on the vacuum chuck. The basic cleaning procedure is to rinse the part in successively cleaner solvent tanks, followed by drag wiping with the solvent. We are currently using toluene for both the rinse and drag wiping operations.

Our experience with drag wiping has not been entirely satisfactory. Even under clean room conditions some very light scratches from drag wiping can occur. Therefore, the number of drag-wipes on a finished surface should be kept as few as possible.

\subsection{Inspecting Finished Crystals}

The surface finish, surface figure, and transmitted wavefront of a finished crystal can be measured using equipment and procedures normally used for transmissive optics, taking into account the additional handling requirements of KDP described in Section 5.6. 
Dimensional inspection of a crystal - measuring the physical dimensions of the part - is done carefully with a micrometer before the crystal faces are finished. The determinacy of the diamond turning process should be sufficient to insure that the calculated final thickness is within tolerance.

The clarity of the finished surfaces is a subjective inspection. Our current method is to back-light the part with a bright collimated light source, such as a microscope light or slide projector, while in a darkened room. The illumination and view angles are adjusted until any visible surface flaws are observed. Dirt on the surface and a damaged surface layer will tend to follow the diamond turning lines and have a similar appearance when observed by this method. Dirt can usually be effected by gently wiping the surface with a cotton swab wetted with toluene, whereas surface damage is not. Scratches from drag-wiping are usually very fine, and nominally do not follow the diamond turning lines.

Point defects on the finished surfaces can be readily observed under a microscope at $100 x$ using an indirect back-lighting technique. The crystal is illuminated from behind with a bright collimated light pointing off the axis of the microscope view direction. With the microscope focused on the opposite surface, defects on it appear as bright scattering sights. As with the clarity inspection method, this one is also a subjective measurement. We have found it useful for making relative comparisons between finished crystals.

\subsection{Conclusion}

The authors have presented a procedure and described the equipment necessary for single-point diamond flycutting (diamond turning) KDP crystals. Both are based on current practices at LLNL. In addition to describing a step-by-step process for diamond turning KDP, specific discussions were included on the necessary diamond tool geometry and edge sharpness, cutting fluid, and crystal preparation, handling, cleaning, and inspection. This work should enable a reader with diamond turning experience and a suitable machine to begin finishing KDP crystals, and provide the necessary framework for developing an indigenous KDP finishing capability.

\subsection{Acknowledgments}

The authors thank L. Jeffrey Atherton and John Marion of the Laser Materials Associate Program at LLNL for their support of this work. Special appreciation is extended to the skilled technical staff in the Manufacturing and Materials Engineering Division at LLNL for their experience, insight, and hands-on efforts: Tony Demiris, Pete Dupuy, Jack Reynolds, Kim Shelley, and Joe Vargas for diamond turning KDP, and Charlie Cass and Brad Fix for building us a suitable diamond turning machine. 


\section{References}

1 B.M. Van Wonterghem, et al, "System Description and Initial Performance Results for Beamlet", ICF Quarterly Report, Volume 5, Number 1, Lawrence Livermore National Laboratory, Livermore, CA, UCRL-LR-105821-95-1, pp 1-17.

2 M.A. Rhodes, et al, "Design and Performance of the Beamlet Optical Switch", ICF Quarterly Report, Volume 5, Number 1, Lawrence Livermore National Laboratory, Livermore, CA, UCRL-LR-105821-95-1, pp 29-41.

3 F. Rainer, et al "A Historical Perspective on Fifteen Years of Laser Damage Thresholds at LLNL", Laser-Induced Damage in Optical Materials: 1993, SPIE Volume 2114, p. 17, October 1993.

4 F.T. Marchi, J.B. Bryan, S.L. Thompson, et al, "Nova KDP Diamond Turning Pre-Procurement Meeting", March 23, 1982 presentation to potential vendors for finishing the Nova laser KDP crystals, Lawrence Livermore National Laboratory, Livermore, CA.

5 S.L Thompson, "Diamond Turning KDP", Script from a July 1984 presentation to the Society of Manufacturing Engineers, Lawrence Livermore National Laboratory, Livermore, CA.

6 J. Huntley, "KDP Diamond Turning Procedure", Private communication from the author, Lawrence Livermore National Laboratory, Livermore, CA (1986).

7 B.A. Fuchs, P.P. Hed, P.C. Baker, "Fine Diamond Turning of KDP Crystals", Lawrence Livermore National Laboratory, Livermore, CA, UCRL-93974 (1986).

8 C.K. Syn, J.S. Taylor, B.A. Fuchs, and S.P. Velsko, "Diamond Turning of Optical Single Crystals", Engineering Research and Development Thrust Area Report FY89, Lawrence Livermore National Laboratory, Livermore, CA, UCRL-5386889, pp. 4-21 thru 4-28.

9 T.T. Saito, C.K. Syn, B.A. Fuchs, and S.P. Velsko, "Diamond Turning of Optical Crystals", Lawrence Livermore National Laboratory, Livermore, CA, UCRL102807 (1990).

10 I.M. Thomas, et al "Processes for the Elimination of Fogging on KDP Crystals Prior to and During Use in Laser Systems", Laser-Induced Damage in Optical Materials: 1991, SPIE Volume 1624, p. 140, October 1991.

11 J.S. Taylor, C.K. Syn, R.R. Donaldson, and S.R. Patterson, "Diamond Turning of Silicon for Optics Applications", Lawrence Livermore National Laboratory, Livermore, CA, UCID-21187 (1987).

12 R.R. Donaldson, C.K. Syn, J.S. Taylor, and R.A. Riddle, "Chip Science: A Basic Study of the Single-Point Cutting Process", Engineering Research and Development Thrust Area Report FY87, Lawrence Livermore National Laboratory, Livermore, CA, UCRL-53868-87, pp. 6-12 thru 6-15. 